\title{
El retraso en la designación parlamentaria de magistrados constitucionales. Esbozo de una propuesta de solución ${ }^{1}$
}

\author{
José Antonio Estrada Marún \\ Doctorando en Derecho \\ Universidad Carlos III de Madrid
}

Recibido: 13.07 .2011

Aceptado: 02.11 .2011

\begin{abstract}
Resumen: El retraso en la designación de magistrados del Tribunal Constitucional amenaza con convertirse en uno de los principales problemas de la composición de los órganos especializados de la jurisdicción constitucional. No se trata de un mero incumplimiento formal de plazos que pueda banalizarse, sino que estamos en presencia de una actitud más grave que muestra el comportamiento estratégico de las fuerzas políticas para influir en la composición del supremo intérprete de la Constitución. Esta situación interfiere el funcionamiento ordinario del Tribunal y no coloca al juez constitucional en la mejor posición para ejercer sus delicados cometidos institucionales. En este trabajo se presentan unas primeras observaciones del retraso en la designación de magistrados constitucionales en España y se somete a discusión una propuesta para evitar el problema.
\end{abstract}

Palabras Clave: Derecho constitucional, Tribunal Constitucional, Juez constitucional, designación de magistrados constitucionales, retraso en la elección de magistrados constitucionales.

\begin{abstract}
The delay in the election of judges of the Constitutional Court threatens to become one of the main problems of the composition of the specialized bodies of constitutional jurisdiction. It is not just a formal breach of terms that can trivialized, but we are in the presence of a more serious problem that shows the strategic behavior of political forces to influence the composition of the supreme interpreter of the Constitution. This interferes with the ordinary functions of the Court and does not put the constitutional judge in the best position to exercise their delicate institutional roles. This paper presents some initial observations of the delay in the election of constitutional judges in Spain and introduces a proposal to avoid the problem.
\end{abstract}

Key Words: Constitutional law, Constitutional Court, constitutional judge, election of constitutional judges, delay in the election of constitutional judges.

\footnotetext{
${ }^{1}$ Quiero agradecer profundamente la lectura y las finas observaciones realizadas a este trabajo por la profesora Ascensión Elvira Perales y el profesor Luis Pomed Sánchez, las cuales han beneficiado la confección del texto. Cualquier errata que se detecte corresponderá, desde luego, a mi exclusiva responsabilidad.
} 
SUMARIO. 1.- Introducción. 2.- La especial relevancia del acto de designación de los magistrados constitucionales. 3.- La composición del Tribunal Constitucional. 4.- La designación de los magistrados constitucionales. 5.- La "toma de decisión". 6.- El retraso en la designación de magistrados constitucionales. 7.- Construyendo una propuesta de solución.

\section{Introducción}

En el historial de las renovaciones de los magistrados del Tribunal Constitucional ha habido casos en que los órganos facultados constitucionalmente para designarlos no han concluido en tiempo el procedimiento selectivo. Como muestra más reciente de lo anterior, recuérdese la designación de magistrados constitucionales realizada por el Senado con un retraso nunca antes visto de tres años ${ }^{2}$. Por otro lado, considérese el retraso en el que actualmente (julio de 2011) incurre el Congreso de los Diputados para renovar el turno de magistrados cuyo mandato finalizó el pasado mes de noviembre de 2010 .

Esta no es, sin embargo, la primera vez que el Senado y el Congreso experimentan retrasos prolongados en la designación de los magistrados constitucionales, ni han sido tampoco los únicos órganos proponentes de magistrados constitucionales que han incurrido en dilaciones de esta naturaleza, sino que todos los órganos llamados a seleccionarlos, en alguna medida, las han llegado a generar. No obstante, deben destacarse significativamente los retrasos ocasionados por los órganos legislativos, porque son los que con mayor frecuencia y prolongación los han padecido, lo que sin duda alguna, está constituyendo uno de los principales problemas de la composición del Tribunal Constitucional español.

El Tribunal Constitucional (TC) no es tampoco el único órgano en España que se ha visto afectado por los retrasos parlamentarios en la designación de sus miembros, puesto que existen precedentes importantes en la designación de los integrantes del Tribunal de Cuentas, del Consejo General del Poder Judicial (CGPJ), del Defensor del Pueblo, entre otros ${ }^{3}$.

${ }^{2}$ El periodo de cargo de los magistrados había finalizado en diciembre de 2007 y fueron renovados hasta la sesión plenaria del Senado del 1 de diciembre de 2010. Las designaciones recayeron en Adela Asúa Batarrita, Francisco José Hernando Santiago, Luis Ignacio Ortega Álvarez, y Francisco Pérez de los Cobos Orihuel. Ver, Cortes Generales, Diario de Sesiones del Senado, IX Legislatura, no. 103, sesión plenaria de 1 de diciembre de 2010.

${ }^{3}$ Sobre el retraso de medio año en la designación de diez vocales del CGPJ, ver Andrés Ibáñez, Perfecto, "La renovación del Consejo General del Poder Judicial", El País, 5 de noviembre de 2001. En cuanto a la falta de designación del Defensor del Pueblo desde la expiración del cargo de Enrique Múgica Herzog el 30 de junio de 2010, puede verse una breve referencia a la interinidad de su titular en el Informe Anual a las Cortes Generales 2010, p. 4. La prensa en su momento recogió el retraso de diez meses en la designación de seis consejeros del Tribunal de Cuentas, ver a título de ejemplo la edición de 31 de octubre de 2001 del diario El País. 
Por otro lado, es necesario considerar que el retraso de las Cámaras parlamentarias para designar a los magistrados constitucionales no es un problema que ocurra únicamente en España, sino que existen manifestaciones de esta índole en otros países que cuentan con un tribunal constitucional o bien otro órgano especializado de jurisdicción constitucional, entre los que se pueden referir los casos de Italia, Alemania, Bélgica, Portugal, Eslovenia, Hungría, Nicaragua, Costa Rica, Perú, Ecuador, Bolivia, entre otros ${ }^{4}$.

Los datos anteriores, dan buena cuenta del grado de generalidad con el que se presenta este problema en la práctica, por lo que se plantea la necesidad de su atención y estudio. En este sentido, también se ha pronunciado la Comisión de Venecia del Consejo de Europa en el marco del informe que realizó sobre la composición de los tribunales constitucionales, concluyendo en la necesidad de adoptar medidas para preservar las funciones de las cortes constitucionales, precisamente en los casos de inacción en la nominación de los jueces por la autoridad correspondiente ${ }^{5}$.

El retraso en la designación de magistrados constitucionales es un delicado problema para el Tribunal, porque constituye una interferencia a su funcionamiento ordinario, que no sólo afecta a su capacidad laboral, sino que también menoscaba la legitimidad y el reconocimiento social de sus delicados cometidos institucionales. La situación de interinidad de los magistrados prorrogados no los coloca en la mejor posición institucional para asumir y resolver los procesos constitucionales. El conflicto político generado en torno al retraso de la designación suele mostrar, así sea de forma aparente, cierta vinculación del magistrado con el partido político que lo propone, y en términos más generales, una suerte de influjo desproporcionado del poder legislativo sobre el TC nada deseable para la independencia del órgano.

El retraso en la designación de magistrados constitucionales implica necesariamente una flagrante violación a la Constitución. No se trata de un mero incumplimiento formal de plazos que pueda banalizarse, sino que estamos en presencia de una actitud más grave y reiterada que trastoca directamente las trazas del modelo de Tribunal Constitucional previsto en la Constitución, como lo es, cuando menos, el sistema de nombramiento, duración del cargo, y la renovación de los magistrados constitucionales.

Con todo ello, no resulta extraño el pronunciamiento crítico cada vez más generalizado de la opinión pública, de las asociaciones de juristas, o de los profesores universitarios, contra la conducta dilatoria de las fuerzas políticas para efectuar la designación. De igual forma, la doctrina comienza a partici-

\footnotetext{
${ }^{4}$ Ver al respecto el trabajo elaborado por el Servicio de Estudio, Biblioteca y Documentación del Tribunal Constitucional titulado "Modelos de renovación personal de Tribunales Constitucionales", REDC, no. 61, 2001, pp. 209-237.

${ }^{5}$ Se trata del documento con clave CDL-JU(1997)010fin, titulado "Rapport révisé sur la composition des Cours constitutionnelles", el cual puede ser consultado en la página web de la Comisión de Venecia del Consejo de Europa.
} 
par en este debate ${ }^{6}$, aunque considero que actualmente el desarrollo de este tema sigue siendo una tarea pendiente. De ahí que me haya parecido pertinente la elaboración de este trabajo a fin de contribuir a buscar una forma de solucionar este problema para garantizar, en mayor medida, el desarrollo normalizado de las competencias del Tribunal Constitucional y su posición institucional.

En este estudio pretendo mostrar unas primeras observaciones sobre el retraso en la designación de los magistrados constitucionales introduciendo, por otro lado, una propuesta para evitarlo. Para ello, dedico algunos apartados a mostrar el contexto, la magnitud y sus consecuencias. Aunque el trabajo se circunscribe al caso español, algunas reflexiones podrían resultar de interés a otras experiencias de justicia constitucional debido a que la dilación en la selección de los jueces constitucionales amenaza con convertirse en uno de los principales problemas de la composición de los órganos especializados de la jurisdicción constitucional.

Quisiera finalmente mencionar dos circunstancias que van a caracterizar este trabajo. Una tiene relación con las fuentes de información y otra con la necesaria vinculación del comportamiento de las fuerzas políticas en el problema.

${ }^{6}$ Entre los trabajos que aluden al tema pueden destacarse los de Fernández Segado, Francisco, "La estructura orgánica del Tribunal Constitucional", en Trujillo, Gumersindo; López Guerra, Luis María y González-Trevijano, Pedro José (Dirs.), La experiencia constitucional (1978-2000), Madrid, CEPC, 2000, p. 446; Pauner Chulvi, Cristina, La designación parlamentaria de cargos públicos, Madrid, Congreso de los Diputados, 2003, p. 187; Santamaría Pastor, Juan Alfonso, "La prorogatio de los órganos constitucionales. Apuntes mínimos sobre un tema que no lo es", REDC, no. 84, 2008, pp. 20-24; Aguiar de Luque, Luis, "Una nueva reflexión sobre la prorogatio de los órganos constitucionales. Una discrepancia y algunas puntualizaciones a J. A. Santamaría", REDC, no. 85, 2009, p. 93; Cruz Villalón, Pedro, "El estado del Tribunal Constitucional", en Bogdandy, Armin von; Ferrer Mac-Gregor, Eduardo; Morales Antoniazzi, Mariela (Coords.), La justicia constitucional y su internacionalización. ¿Hacia un Ius constitucionale commune en América Latina?, t. 1, México, Instituto de Investigaciones Jurídicas, serie doctrina jurídica no. 569, UNAM, Max-Planck-Institut, Instituto Iberoamericano de Derecho Procesal Constitucional, 2010, p. 723; Pajarés Montolio, Emilio (Coord.); Santaolalla López, Fernando; Pauner Chulvi, Cristina, Procedimientos de designación parlamentaria de cargos públicos, Foro democracia y representación, no. 20, Madrid, CEPC, 2010, 134 p; Alzaga Villaamil, Óscar, Del consenso constituyente al conflicto permanente, Madrid, Trotta, 2011, p. 83. En la doctrina italiana pueden mencionarse los trabajos de Miglio, Gianfranco, Una Costituzione per i prossimi trent' anni. Intervista sulla Terza Repubblica a cura di Marcello Staglieno, (3a. ed.), Roma, Laterza, 1991, p. 88-89.; Luther, Jörg, "I giudici costituzionali sono giudici naturali?", Giurisprudenza costituzionale, 1991, p. 2501; Pinardi, Roberto, "Il problema dei ritardi parlamentari nell'elezione dei giudici costituzionali tra regole convenzionali e rimedi de iure condendo", Giurisprudenza Costituzionale, no. 48.3, 2003, p. 1852-1853; Vizioli, Nicola, "L'elezione dei membri della Corte Costituzionale e del Consiglio Superiore della Magistratura da parte del Parlamento in seduta comune", en VVAA., Il rispetto delle regole. Iscritti degli allievi in onore di Alessandro Pizzorusso, Torino, G. Giappichelli, 2005, pp. 247-255. 
Respecto a la primera, considérese que en la actualidad existe un volumen importante de estudios sobre la interpretación constitucional, la independencia judicial y sobre aspectos orgánicos del TC, sin embargo, los procedimientos de designación no son tratados con extensión y lo mismo sucede con los retrasos parlamentarios en su ejecución. Esta circunstancia ha implicado que en el desarrollo del tema se observe entre las fuentes de información reiteradas citas a los boletines oficiales de los órganos legislativos, a las notas al pié en publicaciones periódicas, a las columnas de opinión, entrevistas o discursos de catedráticos y magistrados, a las Memorias del Tribunal Constitucional, a los medios de comunicación escrita, entre otras.

En cuanto a la segunda, creo necesario advertir que el incumplimiento de los órganos proponentes del deber de designar a los magistrados constitucionales en tiempo no se explica si sólo se atiende a las disposiciones jurídicas que norman el procedimiento de designación, debido a que es imprescindible fijar la atención en las circunstancias políticas que rodean el acto, y en alguna medida, en este trabajo se hará referencia a dichas vicisitudes.

\section{La especial relevancia del acto de designación de los magistrados cons- titucionales}

La relevancia específica del acto selectivo de magistrados constitucionales tiene su base en la propia configuración del Tribunal Constitucional. En efecto, la Constitución de 1978 (CE) de forma directa introdujo los atributos fundamentales de la composición, función y posición de la institución estatal, lo que cobra un especial significado pues con ello se corresponde a uno de los criterios que la doctrina generalmente ha formulado para identificar a los denominados "órganos constitucionales del Estado".

La noción que se ha elaborado de "órgano constitucional" implica que son entidades que participan en el proceso de dirección política del Estado, son órganos que ejercen poder soberano y colaboran con la formación de la voluntad estatal. Son órganos que gozan de un ámbito de autonomía orgánica, funcional y presupuestaria. Tienen con respecto al resto de órganos constitucionales una posición de paridad, aunque ello no excluye la existencia entre ellos de controles recíprocos. Entre otras características, se considera además que son órganos necesarios que determinan la forma de gobierno, y que configuran e integran al Estado ${ }^{7}$.

La relevancia del Tribunal Constitucional como órgano constitucional del Estado se destaca además por el concreto contenido de las atribuciones que le reserva la Constitución y su Ley Orgánica (LOTC). El Tribunal se convierte en la institución que además de tutelar en última instancia los derechos fun-

\footnotetext{
${ }^{7}$ García-Pelayo, Manuel, “El ‘status' del Tribunal Constitucional”, REDC, no. 1, 1981, p. 13.
} 
damentales y controlar la regularidad de la distribución de competencias entre los órganos y entidades territoriales del Estado, vela por la adecuación a la Constitución de las normas con rango de ley, lo que la hace competente para conocer y resolver buena parte de los conflictos políticos que se generan entre las mayorías y las minorías parlamentarias, regularmente sobre los temas más sensibles de una sociedad: aborto, matrimonio entre personas del mismo sexo, eutanasia, distribución territorial y funcional del poder, entre otras.

Los partidos políticos son conscientes de que en determinado momento tendrán que llevar a cabo sus funciones de acuerdo a los dictados contenidos en las resoluciones del Tribunal Constitucional, por lo que resulta consecuente que busquen la manera de ejercer determinada influencia sobre ese órgano a través de la participación que ostentan en la designación de sus miembros.

Finalmente conviene introducir la apreciación de que no se trata de un procedimiento selectivo de personal de tipo funcionarial como podría ser la oposición o el concurso, sino que atendiendo a las delicadas competencias del Tribunal Constitucional y el sentido interés que muestran los políticos en la designación de sus miembros, el acto selectivo se convierte en una decisión estratégica y relevante porque adquiere "sentido de Estado" o de dirección política del mismo.

\section{La composición del Tribunal Constitucional}

El modelo de composición del Tribunal Constitucional recibe de la Constitución su expresión en el artículo 159.1 en los términos siguientes: "El Tribunal Constitucional se compone de 12 miembros nombrados por el Rey; de ellos, cuatro a propuesta del Congreso por mayoría de tres quintos de sus miembros; cuatro a propuesta del Senado, con idéntica mayoría: dos a propuesta del Gobierno y dos a propuesta del Consejo General del Poder Judicial”.

El modelo ideado involucra la participación de los poderes del Estado según la clásica teoría de la tripartición en ejecutivo, judicial y legislativo, pero con la acentuada intervención de éste último. Aunque cabe advertir que la participación prevista para la Corona sólo perfecciona formalmente el nombramiento de los magistrados constitucionales, puesto que no ejerce influencia alguna sobre los órganos proponentes: Gobierno, CGPJ, Senado y Congreso.

En cuanto al preponderante papel que desempeñan las Cámaras parlamentarias que eligen a ocho de los doce miembros del TC, se ha señalado que expone al Tribunal a su politización ${ }^{8}$, sin embargo, el modelo contiene un

\footnotetext{
${ }^{8}$ Para González Pérez el predominio del legislativo "excede de lo razonable", para Espín Templado "hace posible alcanzar una cierta sintonía de la Nación y la interpretación de la Constitución por parte del Tribunal". Ver, respectivamente, González Pérez, Jesús, Derecho Procesal Constitucional. Madrid, Civitas, 1980, p. 88; Espín Templado, Eduardo, “Artículo 16", en Requejo Pagés, Juan Luis (Coord.), Comentarios a la Ley Orgánica del Tribunal Constitucional, Madrid, Tribunal Constitucional, Boletín Oficial del Estado, 2001, p. 298.
} 
marco de características que pretenden garantizar la independencia del Tribunal frente al origen político de su nombramiento ${ }^{9}$, entre las cuales, se destacan las exigencias a determinados órganos proponentes de mayorías cualificadas para alcanzar el acuerdo de designación, la renovación periódica del cargo por terceras partes cada tres años sin reelección inmediata, la cualificación técnico-jurídica de los magistrados, y un determinado estatuto jurídico de los mismos.

El Tribunal se compone de 12 miembros nombrados para un periodo de cargo de de nueve años (159.3 CE y 16.3 LOTC). Los magistrados del máximo intérprete de la Constitución deben ser nombrados de entre ciudadanos españoles que sean Magistrados, Fiscales, Profesores de Universidad, funcionarios públicos y abogados. Es necesario además, que los candidatos posean "reconocida competencia", y que cuenten con más de quince años de ejercicio profesional o en activo en la respectiva función. Por otro lado, no se prevé una edad mínima para acceder al cargo, tampoco existe un sistema formal de cuotas para la asignación de magistrados constitucionales que atienda a las diversas carreras jurídicas que refiere el artículo 159.2 de la CE, ni relacionadas con cuestiones de género, lengua o ámbito territorial como sí sucede en otras experiencias extranjeras del entorno ${ }^{10}$.

El sistema de renovación de los magistrados está diseñado para que cada tres años se designen cuatro de ellos, es decir, el órgano se renueva por terceras partes cada trienio. En una ocasión corresponderá seleccionarlos al Senado, en el siguiente periodo al Congreso de los Diputados, en otros tres años y de manera conjunta, al Gobierno y al Consejo General del Poder Judicial, y así sucesivamente ${ }^{11}$.

\footnotetext{
${ }^{9}$ Para Alzaga Villaamil el modelo tiene previsto una serie de garantías que constituyen la contraparte del origen político de su nombramiento, y para Fernández Segado el modelo contiene "frenos frente a la politización". En, Alzaga Villaamil, Oscar, "Sobre la composición del Tribunal Constitucional”, Teoría y Realidad Constitucional, no. 10-1, 2003, p. 167. Fernández Segado, Francisco, “Artículo 159”, en Alzaga Villaamil, Oscar (Dir.), Comentarios a la Constitución española de 1978, Tomo 12, Madrid, Cortes Generales, EDERSA, 1999, p. 9495.

${ }^{10}$ Por ejemplo en Bélgica, el Tribunal de Arbitraje se compone de doce miembros, de los cuales la mitad debe ser de expresión lingüística francesa y el resto forma el grupo lingüístico neerlandés. En Alemania, de los dieciséis integrantes del Tribunal Constitucional Federal seis deben ser jueces federales. En el Consejo Constitucional francés está prevista la integración de miembros natos, esto es, de los expresidentes de la República. En Portugal seis de las trece plazas del Tribunal Constitucional deben ser ocupadas obligatoriamente por jueces de los demás tribunales y las siete restantes quedan reservadas a los "juristas". Favoreu, Louis, Los tribunales constitucionales, Barcelona, Ariel, 1994, pp. 64, 132, 102 y 127 , respectivamente.

${ }^{11}$ La agrupación de nombramientos de los magistrados en terceras partes y el comienzo de la cadencia de renovaciones quedó establecida en la Disposición Transitoria Novena de la Constitución.
} 
La característica de renovación parcial constituye una seña particular del modelo de renovación personal del Tribunal Constitucional español puesto que no es generalmente empleada en las experiencias europeas de justicia constitucional, a excepción de Francia. La doctrina, por otro lado, la entiende como una medida para evitar que la composición del TC propenda a irradiar de manera excesiva "la mayoría parlamentaria existente en un momento dado, permitiendo sin embargo un progresivo reflejo de las nuevas mayorías que puedan surgir posteriormente" 12 . De igual forma, evita cambios bruscos en la composición del Tribunal ${ }^{13}$, estableciendo una dinámica de acoplamiento didáctico entra la nueva y anterior promoción de magistrados en la institución.

La renovación debe activarse, como mínimo, antes de los cuatro meses previos a la fecha de expiración del nombramiento del magistrado. Esta tarea corresponde a la presidencia del Tribunal Constitucional quien debe solicitar a sus homólogos de los órganos que han de hacer las propuestas de designación de los nuevos magistrados, que inicien el procedimiento para ello (17.1 LOTC).

Si la selección se retrasa, los magistrados que han cesado en el cargo continúan "en el ejercicio de sus funciones hasta que hayan tomado posesión quienes hubieren de sucederles" (17.2 LOTC). En este caso, a los nuevos magistrados que fuesen designados se les restará del mandato el tiempo de retraso en la renovación (17.5 LOTC). Los miembros del TC no pueden ser reelegidos para un periodo inmediato, a menos que el magistrado haya ocupado el cargo por un plazo no superior a tres años.

Por otro lado, conviene señalar que el sistema de renovación por tercios no es el único utilizado para designar a los magistrados constitucionales, pues se encuentran los supuestos para cubrir vacantes, tales como el fallecimiento, renuncia, incapacidad, incompatibilidad sobrevenida, entre otras (23 LOTC). Estas vacantes, según el recientemente adicionado párrafo quinto del 17 LOTC, "serán cubiertas con arreglo al mismo procedimiento utilizado para la designación del Magistrado que hubiese causado vacante y por el tiempo que a éste restase".

\section{La designación de los magistrados constitucionales}

Lo primero que habría que resaltar es la previsión de muy pocos aspectos del procedimiento de elección de los magistrados constitucionales tanto en la Constitución como en la LOTC, lo que hace suponer que el legislador prefirió dejar la regulación concreta del procedimiento a las normas de desarrollo que rigen a los órganos proponentes.

\footnotetext{
${ }^{12}$ Espín Templado, Eduardo, “Artículo 16”, Comentarios a la Ley Orgánica del Tribunal Constitucional..., p. 299.

${ }^{13}$ Fernández Segado, Francisco, “Artículo 159”, Comentarios a la Constitución espanola ..., p. 116.
} 
En cualquier caso, desde una perspectiva muy general y atendiendo a la normativa que disciplina a los órganos proponentes, se puede mencionar que el procedimiento que llevan a cabo éstos para designar a los magistrados constitucionales se corresponde a un modelo compuesto de una primera etapa de propuesta y valoración de candidatos a cargo de una comisión, y de una segunda etapa donde aquélla eleva la propuesta al Pleno para que realice la elección con las mayorías calificadas exigidas ${ }^{14}$.

En el caso del CGPJ será la Comisión de Calificación a que hace referencia el artículo 135 de la Ley Orgánica 6/1985, de 1 julio, del Poder Judicial la encargada de emitir un informe para que el Pleno decida con el voto favorable de tres quintos de sus miembros. El Gobierno es el único órgano proponente sobre el cual no se exige una específica mayoría para acordar la selección del magistrado, lo que resulta coherente si se atiende a la preeminencia que ostenta el Presidente dentro del Consejo de Ministros. Se entiende que dentro del proceso de selección existe un mecanismo de análisis previo de los nombres propuestos realizado por la Comisión General de Secretarios de Estado y Subsecretarios, ya que es la encargada de la preparación de todos los asuntos que vayan a someterse a la aprobación del Consejo de Ministros, según lo disponen los párrafos cuarto y quinto del artículo 8 de la Ley 50/1997, de 27 de noviembre, del Gobierno (LG). De cualquier modo, es complicado averiguar la forma en que ha sido perfilada la propuesta del magistrado debido al carácter secreto de las deliberaciones del propio Consejo de Ministros (5.2 LG).

En el Congreso de los Diputados será la Comisión Consultiva de Nombramientos la encargada de informar al Pleno acerca de la idoneidad de los candidatos presentados por los Grupos Parlamentarios, por otro lado, en el Senado es a través de la Comisión de Nombramientos que se prepara la propuesta de designación para presentar en el Pleno, destacando la previsión introducida por la Ley Orgánica 6/2007, de 24 de mayo que modifica la LOTC ${ }^{15}$,

${ }^{14}$ Ver al respecto el trabajo de Fernández Segado, Francisco, "El procedimiento de elección de los magistrados constitucionales", Revista de la Facultad de Derecho de la Universidad Complutense, no. 77, 1991, p. 174.

${ }^{15}$ Esta reforma, a diferencia de las anteriores que se han efectuado, incidió acusadamente en un elevado número de aspectos de trascendencia, que efectivamente ha representado la más amplia y generalizada modificación a la LOTC (32 artículos modificados, 1 disposición adicional y 1 final). Entre las obras que ha sido objeto de estudio se encuentran las de: Balaguer Callejón, Francisco, (Coord.); Cámara Villar, Gregorio; Medina Rey, Luis Felipe, La nueva Ley Orgánica del Tribunal Constitucional, Madrid, Tecnos, 2008, 202 pp.; Fernández Segado, Francisco, La reforma del régimen jurídico-procesal del recurso de Amparo, Madrid, Dykinson-Constitucional, 2008, 197 pp.; Carrillo, Marc (Coord.), Hacia una nueva jurisdicción constitucional. Estudios sobre la ley 6/2007, de 24 de mayo de reforma de la LOTC, Valencia, Tirant lo Blanch, 2008, 397 pp.; García Vázquez, Sonia, La controvertida reforma de la Ley Orgánica del Tribunal Constitucional (2 ${ }^{\mathrm{a}}$ Ed.), Santiago de Compostela, Andavira, 2009, 163 pp. 
por la que previó la posibilidad de que las Asambleas Legislativas de las Comunidades Autónomas presenten propuestas de magistrados constitucionales que, igualmente serán valoradas por la Comisión, y luego presentadas al Pleno ${ }^{16}$.

Conviene señalar una disposición legal que no está contemplada para las designaciones de magistrados del Gobierno y del CGPJ, pero que sí está prevista expresamente en el 16.3 LOTC para las designaciones del Senado y Congreso. Se trata, igualmente de una novedad introducida por la Ley Orgánica 6/2007, de 24 de mayo, consistente en la obligación de comparecencia personal de los candidatos ante la respectiva Comisión de nombramientos de la cámara electora.

\section{La "toma de decisión"}

El artículo 159.1 CE exige que el acuerdo de designación por parte del Congreso y el Senado cuente con el voto favorable de la mayoría de tres quintos de sus miembros. La mayoría que se requiere resulta muy elevada, incluso se trata de la misma que se exige para realizar inicialmente las reformas constitucionales por el procedimiento ordinario $(167.1 \mathrm{CE})$. El establecimiento de esta elevada mayoría obliga en la práctica a que la decisión deba ser acordada entre al menos dos de las principales fuerzas políticas representadas en el Par-

\footnotetext{
${ }^{16}$ Esta reforma, no contó con el apoyo del Partido Popular al considerar que la misma era inconstitucional al desapoderar al Senado de la facultad de designar a los magistrados libremente pues ahora debía constreñirse a las propuestas remitidas por los Parlamentos autonómicos. El conflicto dio lugar a las SSTC 49/2008, de 9 de abril y 101/2008, de 24 de julio, las cuales no han sido bien recibidas por la doctrina. Ver al respecto, a Pulido Quecedo, Manuel, "El juicio del Tribunal sobre su ley orgánica (Entre la oportunidad y la constitucionalidad)", Aranzadi Tribunal Constitucional, no. 6, julio, 2008, pp. 9-11; Sanz Pérez, Ángel, "Comentario a la STC 49/2008: Las fuentes del Derecho parlamentario y el Senado", Aranzadi Tribunal Constitucional, no. 9, septiembre, 2008, pp. 13-28; Fernández-Carnicero González, Claro José, "La STC 49/2008, una sentencia desfalleciente”, Aranzadi del Tribunal Constitucional, no. 10, octubre, 2008, pp. 13-16; Carrillo, Marc, "Comentario a la STC 49/2008, de 9 de abril, que resuelve el recurso de inconstitucionalidad núm. 6729/2007, interpuesto por más de cincuenta Diputados del Grupo Parlamentario Popular del Congreso de los Diputados, contra el artículo único, apartados seis y siete, de la Ley Orgánica 6/2007, de 24 de mayo, por la que se modifica la Ley Orgánica 2/1979, de 3 de octubre, del Tribunal Constitucional", en Carrillo, Marc (Coord.), Hacia una nueva jurisdicción constitucional..., pp. 261-292; Torres Muro, Ignacio, "La reforma de la Ley Orgánica del Tribunal Constitucional y del Reglamento del Senado, puesta a prueba (SSTC 49/2008, de 9 de abril y 101/2008, de 24 de julio)", Revista General de Derecho Constitucional, no. 6, septiembre, 2008, pp. 1-26; Soriano Hernández, Enrique, "Los Magistrados de las CC AA y del Senado: Comentario a la STC 101/2008, de 24 de julio. Apostillas a la STC 49/2008", Aranzadi Tribunal Constitucional, no. 16, 2009, pp. 13-30; Urías, Joaquín, "El Tribunal Constitucional ante la participación autonómica en el nombramiento de sus miembros", Revista d' Estudis Autonòmics i Federals, no. 10, abril, 2010, pp. 207-244.
} 
lamento para poder alcanzarla, con lo cual, se garantiza que la designación no venga monopolizada por el partido político mayoritario.

Este acuerdo parlamentario de designación de magistrados puede generarse de al menos dos formas: una primera podría ser a través del consenso, es decir del convencimiento y adición de la mayor cantidad de voluntades políticas en torno al nombre del magistrado que pretende seleccionarse, o bien podría ser mediante un sistema que se ha denominado "de cuotas" o "consenso previo", método no escrito en el que se hace un reparto de cargos entre los Grupos Parlamentarios atendiendo a su intensidad numérica.

El mecanismo que se ha impuesto en la práctica parece ser este último. En este sentido, cuando se ha presentado la oportunidad de cubrir las vacantes de un periodo de renovación en el TC a cargo de las Cámaras Parlamentarias, las cúpulas de los dos grandes partidos políticos son las que proceden a la negociación del reparto de las plazas para cada uno y los nombres de las personas en quienes recaerá el cargo, "una vez logrado el acuerdo, los dirigentes de cada Grupo transmiten las oportunas instrucciones a sus parlamentarios, que se limitan a ratificar formalmente el acuerdo logrado en sede extraparlamentaria"17. En tales circunstancias, el consenso se ha entendido como una "negociación y reparto de puestos a cubrir en el que no ha importado tanto el perfil de los propuestos como conseguir la aceptación de los propios a cambio de transigir en el nombramiento de los candidatos presentados por otro/s grupo/s parlamentario/s" 18 .

En el reparto de propuestas, suele adjudicarse dos de los cuatro puestos vacantes al partido que se ha hecho con la mayoría, uno de los puestos más se otorga al principal partido de la oposición y el puesto restante podría resultar de un efectivo ejercicio de propuesta, deliberación y consenso entre las diversas fuerzas políticas parlamentarias. En alguna ocasión, cuando los dos partidos mayoritarios han conseguido el acuerdo bilateral, no sólo no han incluido a los candidatos que pudieran presentar los grupos minoritarios, sino que han prescindido abiertamente de ellos en el proceso mismo de negociación ${ }^{19}$. Otras veces los partidos mayoritarios no han logrado el acuerdo entre ellos, por lo que acuden a la negociación con los partidos minoritarios y en-

\footnotetext{
${ }^{17}$ Fernández Segado, Francisco, "La estructura orgánica del Tribunal Constitucional”..., p. 442 .

${ }^{18}$ Pauner Chulvi, Cristina, La designación parlamentaria de cargos públicos, Madrid, Congreso de los Diputados, 2003, p. 146.

${ }^{19}$ Por ejemplo, en el caso de la tercera renovación de magistrados constitucionales a cargo del Congreso de los Diputados en 2001, las fuerzas mayoritarias excluyeron de la negociación al Grupo Parlamentario Catalán de Convergència i Unió. Ver, al respecto, tales manifestaciones expresadas por el portavoz de dicho grupo en, Cortes Generales, Diario de Sesiones del Congreso de los Diputados, Comisiones, no. 346, VII Legislatura, sesión no. 3 , comisión consultiva de nombramientos, 25 de octubre de 2001, p. 11229.
} 
tonces ambas formaciones mayoritarias presentan listas confrontadas a la votación plenaria ${ }^{20}$.

La designación de magistrados constitucionales por el sistema de cuotas, como lo expresa Espín Templado, presenta el inconveniente de que "al trascender a la opinión pública las propuestas iniciales de cada partido los candidatos elegidos pueden resultar en cierto modo marcados para algunos ciudadanos, con el consiguiente riesgo de aparente politización" ${ }^{21}$. O bien, como lo expresa Alzaga Villaamil, "dicho método conduce a que tanto en el mundillo de los profesionales del Derecho como, con frecuencia, entre los meros lectores de la prensa diaria, se convierte en vox populi, en cada renovación, qué magistrados lo son a propuesta del PP, quiénes a propuesta del PSOE, y cual ha sido laboriosamente consensuado. Este etiquetado público de los Jueces constitucionales, aún antes de que hayan tomado posesión, como conservadores o progresistas es un flaco servicio que se le hace a la imagen de independencia frente a los partidos políticos, deseable en todo magistrado, $y$ es un factor que en nada contribuye al necesario prestigio del Tribunal Constitucional a la hora de desempeñar sus delicadas funciones"22.

El consenso previo para repartir las propuestas entre las fuerzas parlamentarias parece una práctica bastante difundida en el Parlamento: en efecto, todo parece indicar que "hoy, nadie convence a nadie en una interlocución pública y ritual" 23 , sino que las decisiones son prefijadas de antemano por los líderes de las fuerzas políticas y luego son transmitidas a los parlamentarios mediante reglas disciplinarias de partido y finalmente son trasladadas a la sede parlamentaria, para dar cumplimiento al trámite de forma ritual. Esta misma tendencia parece también avalada por el Derecho comparado, concretamente en experiencias de justicia constitucional del entorno como puede ser la italiana, alemana, portuguesa, entre otras.

Ese reducido grupo de personas en quienes recae el efectivo peso de la negociación desarticula la idea que intenta darse con la designación de los magistrados a cargo del legislativo, según la cual, pretende imprimirse en el acto selectivo la participación de un órgano plural y representativo ${ }^{24}$.

${ }^{20}$ Un episodio de tales características puede verse en la segunda renovación de magistrados constitucionales a cargo del Congreso de los Diputados, en el cual el PSOE y Convergencia i Unió, presentaron una lista y por otro lado, el PP confeccionó una diversa. Cortes Generales, Diario de Sesiones del Congreso de los Diputados, Pleno y Diputación Permanente, no. 203, IV Legislatura, sesión plenaria de 25 de junio de 1992, pp. 10006-10011.

${ }^{21}$ Espín Templado, Eduardo, "Artículo 16", Comentarios a la Ley Orgánica del Tribunal Constitucional..., p. 297.

${ }^{22}$ Alzaga Villaamil, Oscar, "Sobre la composición del Tribunal Constitucional”..., p. 179.

${ }^{23}$ López Aguilar, Juan Fernando, Minoría y oposición en el parlamentarismo: una aproximación comparativa, Madrid, Congreso de los Diputados, 1991, p. 239.

${ }^{24}$ En el diario El País, en su edición de 17 de junio de 1998, Eliseo Aja, en la nota titulada "La elección de magistrados del Tribunal Constitucional" consideró que el reducido grupo de personas que tomaban la decisión planteaba un "déficit democrático" respecto a la norma constitucional que exige que los magistrados sean nombrados por una mayoría de tres quintos de los senadores. 


\section{El retraso en la designación de magistrados constitucionales}

El proceso de negociación política no sólo se ha convertido en la mayoría de las veces en un espectáculo poco edificante sino que también se ha prolongado más allá del tiempo en que debía ejecutarse la designación de los nuevos magistrados constitucionales. La prensa ha reflejado cómo las fuerzas políticas llegan a anunciar que el acuerdo está casi cerrado, para informar lo contrario al día siguiente en medio de un clima de acusaciones mutuas sobre la intransigencia del otro. Los partidos políticos no han mostrado reparos en posponer la renovación de los magistrados constitucionales a la realización de comicios autonómicos, al debate sobre el estado de la nación, a resoluciones de recursos de inconstitucionalidad, a disculpas públicas de un Ministro por sus declaraciones, o a la espera de que se genere un ambiente político más propicio para el acuerdo o mejor dicho, para anteponer a su obligación de nombrar en tiempo a los magistrados constitucionales, intereses de partido.

Las dilaciones que los órganos parlamentarios han generado son, cuando menos, preocupantes. Para apreciar la magnitud de las dilaciones referidas, considérese que todos los procedimientos de renovación grupal de magistrados constitucionales a cargo del Congreso de los Diputados se han realizado con retrasos importantes. En la primera renovación (1983), el nombramiento de Rubio Llorente, Díez de Velasco, Tomás y Valiente, y Truyol Serra, se realizó con ocho meses de dilación ${ }^{25}$; en la segunda renovación (1992), la designación de Mendizábal Allende, Cruz Villalón, González Campos y Viver

\footnotetext{
${ }^{25} \mathrm{El}$ retraso en la designación de los magistrados transcurrió entre los meses de febrero y septiembre de 1983. La sesión plenaria del Congreso de los Diputados en la que fueron electos es del 27 de septiembre de 1983 y la misma está publicada en el Diario de Sesiones del Congreso de los Diputados, no. 58, II Legislatura, pp. 2734-2735. Sin embargo, en esta publicación no quedó asentado el retraso con el que se efectuaba el nombramiento. No obstante, una referencia de esa dilatada designación sí que puede observarse en el Diario de Sesiones de la segunda renovación de magistrados a cargo del Congreso, en voz del diputado Martín Toval. Ver al respecto, Cortes Generales, Diario de Sesiones del Congreso de los Diputados, Pleno y Diputación Permanente, no. 203, IV Legislatura, sesión plenaria de 25 de junio de 1992, p. 10009. De igual forma se alude al retraso en el trabajo de Fernández Segado, Francisco, "El procedimiento de elección de los magistrados constitucionales"..., p. 168. Es necesario mencionar que en esta ocasión, los nombramientos recayeron en las mismas personas que conformaban el grupo que debía renovarse, esto es, no accedieron nuevos integrantes, sino que se efectuó una reelección. Esta reelección fue posible debido al art. 16.4 LOTC, que la permite en los casos que el magistrado haya ocupado el cargo por un plazo no superior a tres años. Los cuatro magistrados de nómina congresual no habían ocupado el cargo por más de tres años ya que fueron el grupo afectado por el sorteo previsto en la Disposición Transitoria Novena de la CE, por medio de la cual, para la puesta en marcha del modelo de renovación parcial del Tribunal, dispuso que un grupo de cuatro miembros de la misma procedencia electiva tendría que cesar y renovarse a los tres años de la primera elección de los magistrados constitucionales.
} 
Pi-Sunyer, tuvo lugar con cuatro meses de retraso ${ }^{26}$; en la tercera renovación grupal (2001), la elección de García-Calvo y Montiel, Delgado Barrio, Gay Montalvo, y Pérez Vera, se efectuó casi cuatro meses después de la fecha en que había finalizado el mandato de los magistrados cesantes ${ }^{27}$, finalmente, la cuarta renovación, se encuentra al día de hoy (julio de 2011), acumulando un retraso de ocho meses ${ }^{28}$.

El incumplimiento del Congreso de los Diputados en la designación de los magistrados constitucionales en tiempo no varía mucho de lo que ha sucedido en el Senado. Esta Cámara Alta efectivamente en su primera renovación grupal (1989), proveyó de manera puntual sus cuotas de magistrados, sin embargo en la segunda renovación (1998), la elección de Casas Baamonde, Conde Martín de Hijas, Garrido Falla y Jiménez Sánchez, tuvo un retraso alarmante de diez meses ${ }^{29}$, y la tercera renovación (2010), definitivamente sobrepasó con mucho, todos los precedentes, al efectuarse con tres años de retraso $^{30}$.

La dilación en la designación de los miembros del TC no sólo se ha manifestado en los supuestos de renovación parcial de magistrados constitucio-

${ }^{26}$ Los magistrados cesaron en su cargo en el mes de febrero de 1992 y fueron designados los sucesores hasta el mes de junio del mismo año. Cortes Generales, Diario de Sesiones del Congreso de los Diputados, Pleno y Diputación Permanente, no. 203, IV Legislatura, sesión plenaria de 25 de junio de 1992, p. 10009. Ver además, la nota de Pérez Royo, Javier, "Una mala noticia. La renovación del Tribunal Constitucional". El País, 13 de marzo de 1992.

${ }^{27}$ El retraso de casi cuatro meses se efectuó entre julio y octubre de 2001. Ver, Cortes Generales, Diario de Sesiones del Congreso de los Diputados, Comisiones, no. 346, VII Legislatura, sesión no. 3, comisión consultiva de nombramientos, 25 de octubre de 2001, p. 11222.

${ }^{28}$ El periodo de cargo de los magistrados salientes finalizó el 8 de noviembre de 2010, puesto que sus nombramientos fueron publicados el 7 de noviembre de 2001 en el BOE (Reales Decretos 1218/2001, 1219/2001, 1220/2001, 1221/2001, todos de 6 de noviembre). De las cuatro plazas pendientes de renovación, una permanece vacante desde el 18 de mayo de 2008, por el fallecimiento del magistrado Roberto García Calvo. El 13 de junio de 2011, los magistrados Javier Delgado Barrio, Elisa Pérez Vera, Eugeni Gay Montalvo, presentaron sus cartas de renuncia por haber expirado su periodo de cargo, pero no fueron aceptadas por el Presidente del Tribunal Constitucional.

${ }^{29}$ Ver al respecto, la referencia que se hace del retraso acaecido en 1998, en el discurso del Presidente del Tribunal Constitucional, Pedro Cruz Villalón, con motivo del XX Aniversario del Tribunal, recogido en el anexo V de la Memoria 2000 del Tribunal Constitucional. Resultan además de interés los siguientes comentarios: Pérez Royo, Javier, "De mal en peor", El País, 10 de noviembre de 1998; Pradera, Javier, "Manoseos partidistas", El País, 23 de diciembre de 1998.

${ }^{30}$ El periodo de cargo de los cuatro magistrados designados en 1998 finalizó en 2007 y hasta el primero de diciembre de 2010 fueron designados los sucesores (Cortes Generales, Diario de Sesiones del Senado, IX Legislatura, no. 103, sesión plenaria de 1 de diciembre de 2010). Un señalamiento crítico con el retraso de tres años en la designación de los magistrados constitucionales puede verse en el discurso de la Presidenta del Tribunal Constitucional, en el acto de la renovación parcial. En efecto, tal y como lo refiere, se trata del "mayor de la historia de este tribunal". El discurso se encuentra en el anexo V de la Memoria 2010 del Tribunal Constitucional. 
nales, sino que también ha incidido en la mayoría de los casos de cobertura de vacantes producidas por causas distintas a la de la expiración del mandato, concretamente en los supuestos de dimisión y fallecimiento. En este sentido, ha resultado habitual observar la sustitución de magistrados varios meses después de haber presentado la dimisión o con significativa posterioridad al fallecimiento del mismo.

En efecto, en el Congreso, la sustitución de Menéndez y Menéndez en 1980, se llevó a cabo casi tres meses después de que dimitiera ${ }^{31}$; en 1990, la sustitución de Truyol Serra tuvo que esperar seis meses posteriores a su dimisión para que se efectuara ${ }^{32}$, y desde el fallecimiento de García-Calvo y Montiel, en mayo de 2008, no se ha nombrado a quien ocupe la plaza, sumando ya un periodo de retraso de 38 meses (julio de 2011). Por otro lado, en el Senado se registra el caso de la dimisión del magistrado de los Mozos y de los Mozos, en la que se procedió a la designación de su relevo ocho meses después de que le fuera aceptada la renuncia ${ }^{33}$.

El retraso parlamentario en la designación de los magistrados constitucionales, como puede verse, ha sido un fenómeno periódico, pero lo más inquietante es que comienza a apreciarse una cierta tendencia a la complicación del problema. La conducta dilatoria trae también aparejada una evidente alteración del modelo composición del TC ideado por el constituyente y el legislador, ya que el ordinario proceso de renovación escalonado es interrumpido o desfasado por razones estratégicas ajenas a la justicia constitucional. En efecto, si las designaciones se realizan con retraso, se genera una tensión entre el precepto constitucional que fija los nueve años de duración del cargo de magistrado con el que prevé la renovación trienal del TC por terceras partes, debido a que no pueden respetarse ambos al mismo tiempo.

\footnotetext{
${ }^{31}$ La renuncia del magistrado Aurelio Menéndez fue aceptada a principios de octubre de 1980 por el entonces Presidente del Tribunal Constitucional Manuel García Pelayo, y fue sustituido por el magistrado Antonio Truyol Serra, designado por el Congreso de los Diputados el 29 de diciembre de 1980. (Cortes, Diario de Sesiones del Congreso de los Diputados, no. 141, sesión plenaria de 29 de diciembre de 1980, pp. 9092-9093). Resulta de interés para conocer las razones de la dimisión, la entrevista realizada a Aurelio Menéndez por el diario El País, en su edición del 9 de octubre de 1980.

${ }^{32}$ La prensa hizo eco de la carta de renuncia que entregó el magistrado Truyol Serra al Presidente del TC Tomás y Valiente el 5 de diciembre de 1989. El magistrado fue sustituido por José Gabaldón López en la sesión plenaria del Congreso de los Diputados del 27 de junio de 1990. Ver respectivamente, la nota titulada "Antonio Truyol presenta su renuncia irrevocable al Tribunal Constitucional", diario $A B C, 6$ de diciembre de 1989; Cortes Generales. Diario de Sesiones del Congreso de los Diputados. Pleno y Diputación Permanente, no. 47, IV Legislatura, sesión plenaria de 27 de junio de 1990, p. 2286.

${ }^{33}$ La renuncia del magistrado José Luis de los Mozos fue comunicada por la presidencia del Tribunal Constitucional el 11 de octubre de 1991, y el Senado designó como sustituto a José Gabaldón López en la sesión plenaria del 30 de junio de 1992. Cortes Generales. Diario de Sesiones del Senado, no. 122, IV Legislatura, sesión plenaria del 30 de junio de 1992, p. 6608.
} 
Como bien lo explica Rubio Llorente, cuando la renovación de los magistrados cesantes se retrasa, los que vengan a sustituirlos, a veces muchos meses después del momento en que debió hacerse, verán su mandato acortado si la cadencia trienal se mantiene rigurosamente, de manera que su propia sustitución se haga exactamente en nueve años contados a partir de la fecha en que teóricamente debieron ser nombrados; en cambio, si para preservar su completo periodo de nueve años, el mismo se empieza a contar desde la fecha en que efectivamente tomaron posesión, la renovación del TC no podría ser trienal ${ }^{34}$.

Esta evidente tensión entre ambos preceptos provocada por los retrasos en la renovación de magistrados no es reconciliable: o se atiende a la exacta renovación trienal disminuyendo el periodo de nueve años de los magistrados elegidos o bien se atiende a los nueve años completos del periodo de duración sacrificando el exacto cumplimiento de la renovación trienal.

Para preparar la renovación de los magistrados constitucionales a cargo del Congreso en 1992, el TC empezó a computar el periodo de mandato de los magistrados que habrían de renovarse, a partir del momento en que debieron ser designados y no en el que efectivamente fueron nombrados, de manera que los ocho meses que dilataron en efectuar su designación, a la postre, fueron los mismos que perdieron en el disfrute del periodo ordinario del cargo ${ }^{35}$.

Por otro lado, en las renovaciones que tuvieron lugar en 2001 por el Congreso, el TC decidió cambiar de criterio y prefirió computar el plazo de funciones de los magistrados a partir de la fecha en que efectivamente fueron nombrados y respetar el disfrute del completo periodo del cargo, alargando consecuentemente, la renovación trienal en algunos meses. ¿Cuál de estos métodos sería el más adecuado? Sin intentar aquí agotar este debate, se puede mencionar que tanto Rubio Llorente ${ }^{36}$, como Aguiar de Luque ${ }^{37}$, están a favor de privilegiar la duración completa del periodo de nueve años de funciones de los magistrados por lo respetuoso que resulta del principio cardinal de la duración igual de los mandatos ${ }^{38}$.

\footnotetext{
${ }^{34}$ Rubio Llorente, Francisco, "El Tribunal Constitucional”, REDC, no. 71, Madrid, CEPC, 2004, pp. 14-15.

${ }^{35}$ Ibid, p. 14. Aunque a su vez, su periodo de cargo se prorrogó por cuatro meses, tiempo que tardó el Congreso en nombrar a quienes habían de sucederles.

${ }^{36}$ Rubio Llorente, Francisco, "El Tribunal Constitucional”..., p. 16.

${ }^{37}$ Aguiar de Luque, Luis, "Composición y organización del Tribunal Constitucional". En, Aguiar de Luque, Luis y Pérez Tremps, Pablo (Dirs.), Veinte años de jurisdicción constitucional en España, Valencia, Tirant lo Blanch, Instituto de Derecho Público Comparado, Universidad Carlos III de Madrid, 2002, p. 34.

${ }^{38}$ El retraso parlamentario podría afectar de igual forma al periodo de duración ordinaria de tres años previstos por el 9.3 LOTC para los cargos de Presidente y Vicepresidente del Tribunal Constitucional. Al respecto puede citarse el caso de la presidencia de Miguel RodríguezPiñero y Bravo Ferrer, que duró menos de tres años (2 años, 8 meses y 3 semanas). Ver, Santolaya Machetti, Pablo, “Artículo 9", en Requejo Pagés, Juan Luis (Coord.), Comentarios a la Ley Orgánica del Tribunal Constitucional, Madrid, Tribunal Constitucional, Boletín Oficial del Estado, 2001, p. 225, nota al pié número 11.
} 
Por mi parte, me adhiero al criterio de preferir la duración completa del periodo de cargo porque es una norma que resulta más protectora de la función, posición e independencia del juez constitucional, en cuanto a que favorece la certeza y tranquilidad que exige el ejercicio de la labor jurisdiccional del magistrado. Sin embargo, esta postura no ha sido compartida por el legislador. En efecto, la reciente reforma de la Ley Orgánica 8/2010, de 4 de noviembre, añadió un apartado $5^{\circ}$ al artículo 16 de la LOTC, en la que estableció la sustracción del periodo de cargo el tiempo de retraso en la renovación por tercios, y además previó que la cobertura de plazas vacantes se harían "con arreglo al mismo procedimiento utilizado para la designación del Magistrado que hubiese causado vacante y por el tiempo que a éste restase".

Como se puede observar, la reforma privilegió el precepto de la renovación escalonada de magistrados sobre la duración del periodo de cargo en nueve años, lo cual no parece lo más afortunado. Esto es así, porque el legislador se ha decantado por una norma más proclive a reforzar la facultad selectiva de magistrados de los órganos competentes, en lugar de preferir una que resultaba más garantista del núcleo del estatuto del magistrado constitucional.

Por otro lado, considerando esta reforma a la luz del problema del retraso parlamentario en la designación de magistrados, la misma no parece augurar los mejores resultados. En efecto, la legalización del retraso en la designación de magistrados no resulta un especial incentivo para que las fuerzas políticas procedan a efectuar la elección en tiempo, al contrario, la norma allana el camino para producirlo. La legalización del retraso otorga un generoso margen de maniobra a los órganos proponentes para confeccionar el nombramiento de los magistrados constitucionales. Dicho margen, permitirá a los partidos políticos mantener bloqueada la negociación hasta una mejor oportunidad de promover al candidato de su conveniencia, sin importar cuánto tiempo tarde en llegar ese momento.

Ahora bien, volviendo a las observaciones que se hacían al inicio de este epígrafe sobre los retrasos en que han incurrido los órganos parlamentarios en la designación de los magistrados constitucionales, es necesario apuntar que la conducta dilatoria de los partidos políticos suele desarrollarse sin que las autoridades de las Cámaras parlamentarias hayan mostrado algún propósito encomiable para impedirla, a través del ejercicio de sus facultades de gobierno, administración, disciplina, de observancia del Reglamento, de la cortesía y de los usos parlamentarios que ostentan institucionalmente al interior del órgano.

Evidentemente no existe un instrumento jurídico al alcance de las Cámaras parlamentarias o de otro órgano del Estado, incluso del mismo TC, que pueda ponerse en marcha para motivar eficazmente la designación de los magistrados constitucionales en tiempo y revertir la situación. En algunas ocasiones han sido los Presidentes del Tribunal Constitucional los que a través de sus discursos, memorias o comunicaciones a las Cámaras, han recordado a 
los órganos proponentes la falta de elección de los magistrados, sin embargo estas acciones, por útiles que parezcan, no han resultado eficaces para impulsar a los partidos políticos a la provisión de los magistrados constitucionales ${ }^{39}$.

Este comportamiento dilatorio de las fuerzas políticas no me parece incorregible. Es verdad que resultaría complicado conducir el comportamiento de las fuerzas políticas por una senda predeterminada, pero tampoco eso es lo que se pretende. Lo que sí estimo que podría idearse es una modulación de su conducta a través del diseño de un sistema institucional de renovación de los magistrados que sancione el incumplimiento de la renovación de los magistrados constitucionales en tiempo y que prevea de salidas alternativas al sistema de resultar bloqueado por los partidos políticos. Este trabajo pretende someter a discusión una propuesta para evitar el prolongado retraso en la designación de los magistrados constitucionales en el caso español y para ello se dedica el siguiente apartado.

\section{Construyendo una propuesta de solución}

\subsection{La prorogatio y la vacancia del puesto}

Se expresaba anteriormente que la eminente causa de las dilaciones excesivas en la designación parlamentaria de magistrados constitucionales era el comportamiento de los partidos políticos al supeditar el deber de nombrar en tiempo a los magistrados constitucionales a sus intereses estratégicos; sin embargo, se debe considerar también que existe un elemento estructural que coadyuva a fomentar tan reprochables prácticas, esto es, la propia articulación de la prorogatio en el sistema español de renovación del juez de la Constitución. En efecto, el funcionamiento de este instituto jurídico, en el marco del sistema general de renovación de los magistrados, está siendo utilizado, en ocasiones, para fines ajenos para los que fue pensado y se requiere por tanto, la inserción de un ajuste al sistema en el que interactúa.

La prórroga del periodo de cargo de los magistrados constitucionales y el sistema de renovación de los mismos, tal y como actualmente se interrelacionan, no se encuentran condicionados a la concurrencia de requisito material alguno, no cuentan con un límite temporal preestablecido y tampoco prevén sistemas alternativos en caso de que sean mal utilizados.

Ciertamente, el artículo 17.2 LOTC, prevé la prorogatio en los siguientes términos: "los Magistrados del Tribunal Constitucional continuarán en el

${ }^{39}$ Entre los referidos documentos, resultan de especial interés los contenidos en la Memoria anual del Tribunal Constitucional. Específicamente los elaborados por la presidencia con motivo de la presentación de la obra o como anexo en los discursos con ocasión de la renovación parcial de magistrados. Véase al respecto, las Memorias de 2000, 2001, 2002, 2008, 2009 y 2010. 
ejercicio de sus funciones hasta que hayan tomado posesión quienes hubieren de sucederles". Según la fórmula utilizada por el legislador, se entiende que la prórroga de los magistrados constitucionales salientes no necesita mayor procedimiento formal sino que opera de manera automática, comenzará con la fecha exacta en que el periodo del cargo de los magistrados salientes se ha agotado y finalizará hasta el momento en que materialmente tomen posesión quienes hubieren de sucederles, es decir, el límite temporal de la prórroga se deja en manos del órgano al que corresponda renovar a los magistrados.

En estas circunstancias, el órgano proponente podría prolongar a su arbitrio la prórroga ya que ésta no contiene elementos objetivos para finalizarla y además el TC carece de mecanismos jurídicos para hacerla cesar. Con estos elementos no podría descartarse una hipótesis en que las fuerzas políticas deliberadamente retrasen o bloqueen la renovación de los magistrados para mantener una composición del TC que estimen más conveniente a sus intereses, por ejemplo, de cara a la resolución de un determinado proceso constitucional. Si se considera además que la prórroga presupone que el órgano proponente no ha cumplido su deber constitucional de seleccionar a tiempo a los magistrados que le corresponde y que a este incumplimiento la ley no prevé una sanción, se podrá concluir que el diseño de la prorogatio, llega a consentir e incluso a estimular tan negligente comportamiento. Por ello, su diseño no es el más adecuado para evitar el retraso ya que no genera una presión efectiva en el sistema institucional para impulsar al órgano proponente a realizar la designación.

La prórroga, además, como señala Santamaría Pastor $^{40}$, es una técnica que por su naturalidad y aparente bajo coste, invita a su empleo sistemático; en un determinado caso, los partidos políticos pueden sostener a sus candidatos afines y si el acuerdo no fuese conseguido, a la postre, no se plantearía problema en cuanto al funcionamiento del órgano ya que éste no se interrumpiría; puede de igual forma, constituirse como un factor de deslegitimación del órgano prorrogado y de la totalidad de decisiones que adopta dañando la institución.

La prórroga podría generar además una sensación de interinidad que podría repercutir en el ánimo y funcionamiento de quienes se encuentran en dicha situación. En este sentido, parecen tomar relevancia las declaraciones que en su momento realizó a la prensa el Presidente del Tribunal Constitucional, Francisco Tomás y Valiente, en medio del clima del retraso en la segunda renovación de magistrados a cargo del Congreso en 1992, cuando aseguraba que "aún el Constitucional continúa funcionando al 100 por ciento", la actividad "no es enteramente normal porque" -dijo- "actuamos sin pro20-24.

${ }^{40}$ Santamaría Pastor, Juan Alfonso, "La prorogatio de los órganos constitucionales..., pp. 
gramación"41. Quizás por todo ello, Santamaría Pastor sugiere la supresión de la prorogatio o, cuando menos, "un empleo limitadísimo de la misma" 42.

Ahora bien, en tales circunstancias cabría plantearse si sería útil prescindir del instituto de la prorogatio para evitar el retraso parlamentario en la designación de los magistrados constitucionales. Al respecto, Santamaría Pastor $^{43}$ considera que su eliminación sería conveniente porque el eventual riesgo de paralización del Tribunal por falta de renovación de los magistrados, sería una situación mediáticamente tan escandalosa que podría resultar políticamente perjudicial a los grupos parlamentarios, lo que les constreñiría a conseguir un acuerdo para designar a los magistrados constitucionales dentro de los plazos. Sin embargo, habría que considerar que una eventual paralización del Tribunal constituye verdaderamente un supuesto muy lejano, ya que el quórum funcional del Pleno y las Salas es el de dos tercios de los miembros que en cada momento las compongan (art. 14 LOTC).

Además, como bien lo apunta Aguiar de Luque ${ }^{44}$, no parece que la situación mediáticamente escandalosa que pudiera generarse vaya a impulsar a las fuerzas políticas, puesto que "siempre hay grupos que obtienen un mayor beneficio que otros con el mantenimiento del statu quo y con la actitud de bloqueo". En efecto, baste recordar los episodios de selección de magistrados, para comprobar que el eventual desgaste político del prolongado retraso parlamentario en su designación, es excusado por estas reprochando la culpa a la fuerza contraria. Mientras tanto, el criterio que prevalece es usar el nombramiento como moneda de cambio para realizar las transacciones políticas más convenientes.

Frente a la tesis de Santamaría Pastor de una generalizada supresión de la prorogatio, Aguiar de Luque la considera aventurada, pero la estima viable, si se implementase con otras medidas que tomasen en cuenta las particularidades del Tribunal Constitucional, por ejemplo la regulación de las funciones que podría desempeñar este en la situación que excepcionalmente se colocaría con ocho de sus miembros; de antemano considera que "no tendrían por qué descartarse que las tareas habitualmente encomendadas a las Salas pudieran seguir siendo desempeñadas, incluso -si fuera necesario- rebajando el quórum actual para la constitución de éstas". Sí cree en cambio, que el Tribunal reducido debería tener vedado la resolución de recursos de inconstitucionalidad para sentar nueva doctrina o conflictos de competencia ${ }^{45}$.

\footnotetext{
${ }^{41}$ Nota de El País de 31 de mayo de 1992, titulada "Tomás y Valiente propone una fórmula de autorrenovación del Constitucional". 19.

${ }^{42}$ Santamaría Pastor, Juan Alfonso, "La prorogatio de los órganos constitucionales..., p.

${ }^{43}$ Ibid, p. 25.

${ }^{44}$ Aguiar de Luque, Luis, "Una nueva reflexión sobre la prorogatio de los órganos constitucionales. Una discrepancia y algunas puntualizaciones a J. A. Santamaría", REDC, no. 85, 2009, p. 90.

${ }^{45}$ Ibid, p. 93.
} 
Ahora bien, sin intentar rebatir exhaustivamente las anteriores opiniones, en mi concepto no parece aconsejable la eliminación de la prorogatio. Para ello resulta de orientación el caso italiano, en el cual no se contempla dicha institución y cuya experiencia no parece aportar los mejores resultados. En efecto, el párrafo cuarto del artículo 135 de la Constitución italiana, establece expresamente que a la finalización del periodo de funciones del juez constitucional éste debe cesar en el cargo y en el ejercicio de las funciones. Consecuentemente si a la terminación del periodo de cargo del juez constitucional no se encontrase seleccionado el sucesor, el puesto quedará vacante.

En una ocasión, por falta de renovación parlamentaria de los jueces más la confluencia de legítimos impedimentos de otros, la Corte tuvo tantas ausencias que se vio obligada a no poder funcionar debido a la imposibilidad de lograr el quórum ${ }^{46}$. Es verdad que se había tratado de un caso extremo, sin embargo, Roberto Pinardi reflejó bastante bien cómo desde 1959 a la fecha, se han presentado numerosos casos en que se ha retrasado la selección de los jueces constitucionales manteniendo a la Corte sin sus 15 miembros y arriesgándola cada vez más a eventuales parálisis ${ }^{47}$. De ahí que incluso la misma doctrina italiana se haya planteado, la previsión de la prorogatio a fin de mantener completa la Corte. No obstante, también han reconocido algunos de los riesgos a los que ya se ha aludido en este trabajo sobre el uso de la prórroga, es decir, la posibilidad de que a través de ella se "dé vida a retrasos instrumentales, dirigidos a influir, en alguna medida, sobre la actividad decisoria del juez de las leyes" ${ }^{\prime 4}$.

El TC español, como ya se ha mencionado, está conformado por 12 magistrados que se renuevan en grupos de cuatro cada tres años, lo que supondría que en el caso de que se genere un retraso parlamentario en la designación de los nuevos magistrados, la regla italiana de la supresión de la prorogatio y la vacancia del puesto, provocaría que el Tribunal estuviera fatalmente expuesto a quedarse sin cuatro integrantes cada tres años, lo que podría plantear en un caso extremo, una situación de inestabilidad que no parece la más óptima para el Tribunal Constitucional: ante la falta de sustitución de los cuatro

\footnotetext{
${ }^{46}$ Panizza, Saulle, "Composizione, organizzazione e funzionamento della Corte Costituzionale", en Romboli, Roberto (a cura di), Aggiornamenti in tema di processo costituzionale (2002-2004), Torino, G. Giappichelli, 2005, p. 3, nota 7. De forma similar, en Ecuador un retraso de tres años en la sustitución parlamentaria de los magistrados constitucionales y pese a la prorogatio contemplada en el modelo ecuatoriano, provocó que en una ocasión no se alcanzara el quórum necesario al renunciar algunos magistrados prorrogados a continuar en el cargo (VV.AA., "Modelos de renovación personal de Tribunales Constitucionales..., p. 224, nota 29).

${ }^{47}$ Pinardi, Roberto, "Il problema dei ritardi parlamentari nell'elezione dei giudici costituzionali tra regole convenzionali e rimedi de iure condendo", Giurisprudenza Costituzionale, no. 48.3, 2003, p. 1823-1824.

${ }^{48}$ Ibid, p. 1847.
} 
miembros podrían unirse supuestos de fallecimiento, recusación o legítimo impedimento de los magistrados, que colocarían al Tribunal en una situación quizás no de parálisis funcional ${ }^{49}$ como sucedió en Italia, pero sí en una posición endeble para resolver los procesos constitucionales sin la completa integración de los titulares de la jurisdicción constitucional.

Por todo lo anterior, el planteamiento sobre la eliminación de la prorogatio y la consecuente vacancia del puesto para el modelo español, es desaconsejable. En España, si bien la forma en que está configurada la prorogatio ha generado sus problemas, lo cierto es que la misma ha logrado garantizar una cierta tendencia a mantener completa la integración del TC, lo que resulta más deseable a la eventual disminución alarmante de los miembros del Tribunal o incluso, en un caso muy extremo, de parálisis funcional. Quizás por el camino donde debía transitarse, sería el de la modificación del modelo español de la prorogatio adicionando un elemento que aleje su periodo de finalización de la entera disponibilidad de los órganos proponentes.

\subsection{Plazo predeterminado para el nombramiento}

Conscientes de las ventajas que conlleva la previsión de la prorogatio en el sistema de renovación de los magistrados constitucionales en España, cabría entonces averiguar el mecanismo que debería introducirse en la articulación del procedimiento de renovación y la prorogatio para que no se haga mal uso de ésta. El componente alternativo utilizable para evitar que sea la prorogatio prolongada excesivamente en el tiempo, ¿podría ser el establecimiento de un plazo predeterminado al órgano proponente para que proceda a designar a los magistrados constitucionales?

Este planteamiento tiene actualmente una manifestación en sede parlamentaria, puesto que se encuentran en trámite en el Congreso de los Diputados (julio de 2011) tres propuestas de modificación al artículo 17 LOTC. Las tres tienen por objeto imponer un límite temporal a la prórroga introduciendo el plazo de seis meses contados a partir de la fecha de expiración de los nombramientos de los magistrados cesantes, previendo además la finalización inmediata y automática de sus $\operatorname{cargos}^{50}$. Las propuestas, sin embargo, por más

\footnotetext{
${ }^{49}$ Por lo menos en el funcionamiento del Pleno y las Salas, al parecer no cabría una eventual parálisis debido a que el 14 LOTC, prevé la posibilidad de "adoptar acuerdos cuando estén presentes, al menos, dos tercios de los miembros que en cada momento lo compongan”. Esto es, el quórum no toma como referencia la completa integración de los doce miembros del Tribunal, si no que parece atender a la composición que efectivamente se verifique en la época de celebración de las sesiones. Quizá donde se podría plantear con mayor probabilidad una parálisis funcional sería en las Secciones, en las cuales el mismo artículo exige la presencia de dos miembros.

${ }^{50}$ Se trata de las propuestas presentadas por el Grupo Parlamentario Catalán Convergència i Unió, del Grupo Parlamentario de Esquerra Republicana-Izquierda Unida-Iniciativa per Catalunya Verds y la remitida por el Senado, formulada por el Grupo Parlamentario Entesa
} 
sugerentes que parezcan, no considero que puedan resolver el problema de fondo, esto es, evitar o inhibir la conducta dilatoria de las fuerzas políticas.

Es verdad que la implementación de un plazo resultaría útil, pero por sí mismo no impediría los retrasos parlamentarios en la designación de los magistrados constitucionales. Podría ser útil porque en principio, motiva a pensar en algunas ventajas, como lo puede ser el intento de objetivar el término de la prórroga de los magistrados cesantes prevista por el 17.2 LOTC, imponiendo un límite temporal a la misma, lo que en un sentido más amplio vendría a dotar al procedimiento de renovación de mayores índices de certeza jurídica. La finalización de la prórroga ya no estaría en manos de las Cámaras parlamentarias o mejor dicho, hasta el momento en que estas consiguiesen el acuerdo, sino que el término de la misma vendría con el natural paso del tiempo.

Ahora bien, dicho lo anterior, me decanto por creer que el plazo por sí mismo no evita el retraso. Para ello, resulta particularmente revelador el caso del artículo 17.1 LOTC, puesto que resulta constantemente vulnerado. En efecto, se trata del plazo de cuatro meses previos a la terminación del cargo de los magistrados constitucionales salientes, para que la presidencia del TC comunique a los órganos proponentes que inicien el procedimiento de selección de los nuevos. En la práctica, ese plazo ha finalizado y los órganos legislativos no han conseguido elegir a los sucesores e incluso han ocupado mucho más tiempo demorando en exceso la renovación de los magistrados.

Esta misma tendencia de incumplimiento de plazos parece ser confirmada en otras experiencias constitucionales. Puede acudirse de nueva cuenta al caso italiano, en donde el modelo de renovación de jueces constitucionales establece el plazo predeterminado de un mes para que los órganos proponentes procedan a la designación de los jueces constitucionales (artículo 5.2 de la ley constitucional 2/1967), sin embargo, el mismo ha sido reiteradamente desatendido en la práctica por el Parlamento ${ }^{51}$. La razón esencial del poco respeto

Catalana de Progrés y Convergència i Unió. Ver, respectivamente, Boletín Oficial de las Cortes Generales, Congreso de los Diputados, IX Legislatura, Serie B, proposiciones de ley, no. 253-1, 4 de junio de 2010; Boletín Oficial de las Cortes Generales, Congreso de los Diputados, IX Legislatura, Serie B, proposiciones de ley, no. 244-1, 30 de abril de 2010; Boletín Oficial de las Cortes Generales, Congreso de los Diputados, IX Legislatura, Serie B, proposiciones de ley, no. 266-1, 23 de julio de 2010.

${ }^{51}$ Considérese que entre 1959 y 1991 , de los diecisiete jueces constitucionales que le correspondió elegir al Parlamento, siete fueron elegidos en un tiempo mayor al mes de plazo, acumulando entre todos estos un retraso aproximado de treinta y siete meses. Por otro lado, de 1992 a 2003, el retraso sumado entre los cinco jueces electos en ese periodo, fue de setenta y cuatro meses. Es decir, el retraso medio va en aumento, pasando de poco más de dos meses para los primeros diecisiete jueces, a los casi quince meses para los sucesivos, llegando a un extremo de casi veinte meses en el caso de la elección del Juez Marini realizada el 18 de junio de 1997 (Vizioli, Nicola, "L'elezione dei membri della Corte Costituzionale..., p. 251; Pinardi, Roberto, "Il problema dei ritardi parlamentari nell'elezione dei giudici costituzionali..., pp. 1823-1824). 
al plazo resulta coincidente con la realidad española, esto es, que no ha constituido un verdadero estímulo a las fuerzas políticas para que realicen el nombramiento en ese tiempo ${ }^{52}$. No parece pues, la opción más eficaz. Quizá para que los plazos tuvieran mayores resultados, deberían venir acompañados de una disposición que sancione su incumplimiento.

\subsection{Facultad de propuesta al Tribunal Constitucional}

Retomando la idea de la previsión de un plazo predeterminado para que los órganos proponentes procedan a la designación de los magistrados constitucionales, pero adicionalmente contemplando una sanción a su incumplimiento a efecto de dotar de mayor eficacia al plazo, se puede plantear la posibilidad de que una de las sanciones o consecuencias a dicho incumplimiento sea la creación de una facultad de propuesta de los magistrados constitucionales a cargo del Tribunal Constitucional, a fin de apurar el procedimiento selectivo.

Una propuesta del género fue ya utilizada en la experiencia alemana de justicia constitucional, motivada por el caso "límite" consistente en los dos años de retraso parlamentario en la designación de los magistrados constitucionales en la disputa político-constitucional sobre la creación de un ejército federal ${ }^{53}$. En esa ocasión, se reformó la Ley del Tribunal Constitucional Federal alemán para establecer la posibilidad de que el Pleno del Tribunal formulase propuestas de candidatos de carácter consultivo ${ }^{54}$, después de que dentro de los dos meses siguientes a la conclusión del mandato del magistrado o de la terminación anticipada de su cargo, los órganos proponentes no hayan designado sucesor y siempre que el más antiguo de los integrantes de la Comisión encargada de elegir a los magistrados por parte del Bundestag o el Presidente del Bundesrat le hayan invitado a hacerlo (artículo 7a).

En Alemania esta propuesta consultiva del Tribunal Constitucional Federal, tal como está diseñada, no ha evitado las dilaciones prolongadas en la selección parlamentaria de magistrados constitucionales. En la práctica no ha

\footnotetext{
${ }^{52}$ Nicola Vizioli, explica que cuando finaliza el periodo de mandato de un juez constitucional (en Italia la renovación de los jueces no es grupal, sino de carácter individual), las fuerzas políticas italianas no proceden de inmediato a su sustitución, sino que mantienen la plaza vacante, hasta en tanto no finalice el periodo de mandato de otro juez, a fin de que los cargos a cubrir sean dos. Habiendo dos plazas para cubrir, la negociación entre los principales partidos políticos se torna más segura, porque en el mismo momento de la designación de ambas, se garantiza en el acto que cada fuerza nombre a uno ("L'elezione dei membri della Corte Costituzionale"..., p. 252).

${ }^{53}$ Geck, Wilhelm Karl, "Nombramiento y status de los magistrados del Tribunal Constitucional Federal de Alemania", REDC, no. 22, 1988, p. 181 y p. 186, nota 18.

${ }^{54}$ Schlaich, Klaus, "El Tribunal Constitucional Federal Alemán”, en Favoreu, Louis; Luchaire, K., et al., Tribunales constitucionales europeos y derechos fundamentales, Madrid, CEPC, 1984, p. 145.
} 
sido frecuente que los órganos proponentes inviten al Tribunal a realizar propuestas y cuando lo han hecho, pocas han sido acogidas ${ }^{55}$. Con estos antecedentes, la formulación de la propuesta para el caso español no se antoja operativa. Sin embargo, la propuesta supone algunas reflexiones que pueden mejorarla. Una de ellas, está referida al medio por el cual se activa la posibilidad de que el Tribunal formule la propuesta y la otra tiene relación con la fuerza vinculante que pudiese tener la misma.

En la primera de ellas se atiende a que el Tribunal necesita de la "invitación" del órgano proponente moroso como condición sine qua non para formular la propuesta. Esta característica podría plantear en principio, la curiosa situación de que la facultad de invitación a la formulación de propuestas, recaiga precisamente en quienes son los responsables de no proveer en tiempo a la designación de los magistrados, lo cual podría augurar sus pocas probabilidades de éxito. Sin embargo, suponiendo que efectivamente las fuerzas políticas procediesen a invitar al TC a su formulación, el carácter consultivo de las mismas no las haría determinantes para impulsar la designación de los magistrados sin mayor retraso.

En apoyo de lo anterior, pudiera recordarse una situación similar acaecida en España en la segunda renovación grupal de magistrados constitucionales a cargo del Congreso de los Diputados en 1992, en la cual, ante la falta de consenso para designar en tiempo a los magistrados, el Partido Popular invitó a las asociaciones profesionales de jueces y fiscales para que formularan propuestas de candidatos para el TC; en aquélla ocasión el PP asumió esa lista de propuestos, sin embargo las mismas no lograron ser consensuadas con el PSOE y cada partido político llevó por separado sus listas a votación por el Pleno $^{56}$.

Esta podría ser la misma suerte de las propuestas presentadas por el TC. Como se puede observar, la posibilidad de que se acuda a otras corporaciones para la formulación de propuestas no parece que genere mayores dificultades debido a que las mismas pueden presentarse, pero al final, no aprobarse y mantener la designación bloqueada. Por ello, el elemento relevante de una facultad de propuesta, tiene que ver con la fuerza vinculante que esta pudiera tener.

Probablemente la propuesta a cargo del Tribunal Constitucional sería más eficaz si no fuese accionada mediante invitación, sino que se articulara con la fuerza de una facultad de nombramiento establecida legalmente, con plenos

${ }^{55}$ El Tribunal en 31 años (1956-1987) ha hecho en cinco ocasiones este tipo de sugerencias y los órganos proponentes "sólo las han seguido ocasionalmente" ("Modelos de renovación personal de Tribunales Constitucionales"..., p. 227.).

${ }^{56}$ Ver al respecto la participación del diputado Trillo-Figueroa. Cortes Generales, Diario de Sesiones del Congreso de los Diputados, Pleno y Diputación Permanente, no. 203, IV Legislatura, sesión plenaria de 25 de junio de 1992, p. 10008 y ss. 
efectos electivos y no, como se ha formulado en Alemania, con efectos consultivos. Podría tratarse de una facultad de nombramiento del Tribunal para seleccionar definitivamente a los miembros faltantes luego de que el Parlamento no la ejerciese en determinado tiempo, todo ello sería al estilo del Tribunal Constitucional portugués, que coopta directamente a tres de sus miembros.

\subsection{La cooptación por el Tribunal Constitucional}

De los trece miembros del Tribunal Constitucional portugués diez son designados por la Asamblea de la República y luego los diez jueces constitucionales elegidos cooptan a los tres restantes. Esta fórmula de composición fue criticada en sus inicios por alguna parte de la doctrina lusa, pero actualmente la tendencia general es el reconocimiento positivo de la institución en gran parte debido al desempeño prudente y de calidad de los jueces constitucionales que han sido elegidos. No obstante, se conservan algunos sectores minoritarios críticos en la forma de composición del Tribunal que la estiman "partidizada" lo que le impide -según los críticos- un grado de independencia equiparable a la de los "verdaderos" tribunales ${ }^{57}$.

Al margen de dicho debate, el desarrollo en la práctica del modelo de composición ha dejado ver las dificultades del consenso parlamentario para designar a los diez jueces constitucionales revelando retrasos en los procesos de designación; por el contrario, en la designación de los tres jueces cooptados, se destaca la mayor facilidad para lograr el consenso entre los miembros del Tribunal Constitucional para elegir a sus compañeros. Asimismo, se presenta entre las ventajas de la cooptación "un cierto distanciamiento a una intervención exclusiva de los directorios de los partidos políticos en la selección de los jueces" ${ }^{\prime 5}$, porque tal y como ya se vio, el procedimiento de cooptación luso se desarrolla en un ámbito dominado por el colegio de los diez jueces constitucionales del Tribunal.

En la experiencia constitucional portuguesa, se subraya además, la facilidad que supone en la cooptación del nombramiento del juez número trece, que como número impar y eventual poseedor del voto de desempate, desata más dificultades para lograr un acuerdo en el seno del Parlamento que en el colegio formado por los diez jueces ya electos ${ }^{59}$.

${ }^{57}$ De Araújo, António y Teles Pereira, J. A., “A justiça constitucional nos 30 anos da constituição portuguesa: Notas para uma aproximação ibérica”, en Tajadura Tejada, Javier (Coord.), La Constitución portuguesa de 1976. Un estudio académico treinta años después, Madrid, CEPC, 2006, p. 209 y 214.

${ }^{58}$ Moreira Cardoso da Costa, José Manuel, "Tópicos sobre competencias e integración del Tribunal Constitucional en Portugal", Ius et Praxis, no. 1, 2002, p. 331.

${ }^{59}$ Ibidem. 
Con las referidas ventajas expresadas por algunos representantes de la doctrina portuguesa, valdría la pena preguntarse si este elemento del sistema de composición portugués conseguiría evitar en la experiencia española el problema del retraso parlamentario en la designación de los magistrados constitucionales. Al respecto, podrían considerarse algunas reflexiones en torno a la probable utilización de la cooptación portuguesa en el Tribunal Constitucional español.

En primer lugar, el funcionamiento del modelo de cooptación adoptado por el Tribunal Constitucional luso resulta de interés. Se trata concretamente de un modelo que, atendiendo a la clasificación elaborada de la institución en general por Loewenstein ${ }^{60}$, se conoce como un sistema de "cooptación electiva directa", consistente en un procedimiento a través del cual a una persona le es confiada una carga o una función de parte de un reducido grupo de electores. El funcionamiento mismo de este procedimiento electivo, permite presumir una elección más pacifica y la eliminación de interferencias ajenas al órgano que elije. La cooptación electiva directa es un importante elemento del proceso potestativo que se desarrolla en el interior de las organizaciones; asimismo, constituye un medio para mantener a los miembros de un grupo que ya existe y que el mismo decide los criterios de quienes pasarán a formar parte de él.

En segundo lugar, el funcionamiento de la cooptación aplicada para la elección de los magistrados, alejaría del Tribunal Constitucional español la lógica de mayorías y minorías presente en las designaciones parlamentarias de los magistrados constitucionales, por lo que podría bloquear los intereses particulares que están detrás de los partidos políticos y en su lugar, vendría a privilegiar el interés de la composición integral de la institución por los sujetos que principalmente están atraídos a su conservación, es decir, sus propios miembros ${ }^{61}$.

La cooptación a cargo del Tribunal, no supondría un proceso de elección ciego, sino que presentaría bastantes posibilidades de que los cooptantes se informasen sobre la capacidad de las funciones del candidato, prestigio, especialización profesional, etc. pudiendo con ello garantizar el perfil que se exige legalmente de los miembros del Alto Tribunal. La cooptación pudiera representar además, un medio para dar acceso a miembros expertos en determinadas materias que estime necesarios el colegio, teniendo la posibilidad incluso aquellas personalidades que no tendrían oportunidad alguna de acceso a través de elecciones necesariamente dominadas por los partidos políticos.

${ }^{60}$ Loewenstein, Karl, Le forme della cooptazione. I processi autonomi di riproduzione dei gruppi privilegiati, Milano, Giuffrè, 1990.

${ }^{61}$ Ibid, p. 242. 


\subsection{Una propuesta de solución: el traslado eventual de la facultad parla- mentaria de selección de magistrados constitucionales al Pleno del Tri- bunal Constitucional}

Con las consideraciones anteriores, podemos someter a discusión la propuesta consistente en la introducción de un plazo predeterminado y perentorio de tres meses, para que las Cámaras Parlamentarias procedan a la selección de los magistrados constitucionales; si luego de transcurrido este plazo no se hubiese proveído la selección, a efectos de una "sanción institucional", la Cámara proponente perderá por esa ocasión la facultad de nombramiento y ésta pasará al Tribunal Constitucional, el cual, dentro de un corto plazo, proveerá a la designación mediante acuerdo del Pleno.

Sostengo esta propuesta porque considero que la eventual pérdida de la facultad de nombramiento de las Cámaras parlamentarias, podría representar un efectivo impulso para que las fuerzas políticas presentes en éstas, procedan a realizar la designación de los magistrados en tiempo. La pérdida de un derecho o una facultad en virtud de no ejercerla en el tiempo otorgado para ello es una regla aplicada en el ámbito del Derecho procesal bastante difundida que podría servir de aplicación para este caso. La pérdida de un derecho por no ejercerlo en determinado plazo tiene por objeto dar certeza jurídica y además constituye un mecanismo que garantiza el desarrollo y la consecución de los pasos de un proceso jurisdiccional o administrativo hasta su finalización.

Con esta medida podría garantizarse la continuidad ordinaria del procedimiento de renovación de los magistrados constitucionales hasta su toma de posesión en el cargo. Seguramente esta sanción no solucione el problema político inmerso en el retraso parlamentario, sin embargo, sí que impediría que las manifestaciones de éste, afectasen o interfiriesen lo menos posible en la composición del Tribunal Constitucional.

En principio, la propuesta no alteraría el modelo actual de composición y renovación de los magistrados constitucionales y no se prescindiría de la participación de los órganos parlamentarios, sino que se establece una medida subsidiaria para desbloquear el procedimiento selectivo y garantizar la completa integración del Tribunal, así como su ordinario funcionamiento.

El plazo de tres meses que se propone para proveer el nombramiento, constituye una nota prudente e importante para ordenar la ejecución de actos procesales y pretende objetivar el límite del periodo en que los magistrados cesantes pueden permanecer prorrogados. Este plazo se formula considerando los cuatro meses previos que tiene el órgano proponente para proveer el nombramiento (17.1 LOTC), de manera que el nuevo plazo vendría a ser sólo un tiempo más de "gracia" o de transición entre las sustituciones de los magistrados constitucionales. En rigor, la suma de los plazos arrojaría un periodo general de siete meses para efectuar la designación del magistrado, el cual se presenta lo suficientemente amplio como para que sea efectuado dentro de los periodos de trabajo parlamentario de la respectiva Cámara, con el corres- 
pondiente periodo deliberativo que puede esperarse de los procedimientos de designación de altos cargos públicos.

En tales condiciones, la prórroga del ejercicio de las funciones de los magistrados prevista por el 17.2 LOTC sólo operaría por tres meses. Consecuentemente, la prórroga no podría ser prolongada excesivamente en el tiempo tal y como ha sucedido, ya que a los tres meses de que las Cámaras parlamentarias no realizasen la designación de los magistrados constitucionales perderían la facultad de su nombramiento y ésta se transferiría al propio TC, quien proveería los nuevos magistrados, dando término efectivo a la prórroga de los magistrados cesados.

Por otro lado, como complemento de la propuesta, se introduciría el establecimiento de un plazo para que el Pleno del Tribunal Constitucional procediese a la designación de los magistrados faltantes. La duración del plazo tendría que ser necesariamente corto, quizá entre los diez - como en Portugal- o quince días hábiles. El periodo, en términos reales, podría traducirse en cerca de veintidós días, los cuales resultarían adecuados para que los magistrados confeccionasen delicadamente sus propuestas de candidatos, que el Presidente del TC procediera a convocar al Pleno y fueran deliberadas en una o varias sesiones, y finalmente decididas con el acuerdo favorable del Pleno.

El acuerdo plenario debería verificarse de acuerdo al quórum funcional del 14 LOTC, esto es la presencia de al menos dos tercios de los miembros que en cada momento compongan el Pleno, y además se regiría por la regla de votación del 9.2 LOTC prevista para la elección del Presidente y Vicepresidente del Tribunal, únicamente en lo relativo a la necesidad de la mayoría absoluta para la primera votación y de mayoría de votos para la segunda. Con relación al procedimiento para que el Pleno realice la cooptación, podría resultar orientativo el estipulado en los artículos 17 a 19 de la Ley que regula al Tribunal Constitucional portugués, en cuanto a que previene detalladamente la presentación de las propuestas, la discusión, el procedimiento y rondas de votación, el escrutinio, el acuerdo de designación y la formalización del cargo.

El procedimiento de elección a cargo del Tribunal supone una mayor distancia del influjo que pudieran introducir los partidos políticos en el proceso selectivo y deja al Tribunal mayores márgenes para defender el desarrollo ordinario de sus competencias y su completa integración. La cooptación ha dado buenos resultados en Portugal y por eso, creo que podría ser de recibo en España.

Servirían de apoyo a esta propuesta, las iniciales recomendaciones que Kelsen ${ }^{62}$ formuló para la conformación de los Tribunales Constitucionales. En efecto, dentro de una serie de ellas, consideró la posibilidad de que se dejase al propio Tribunal el derecho a elegir a algunos magistrados. Esta posi-

\footnotetext{
${ }^{62}$ Kelsen, Hans, La garantía jurisdiccional de la Constitución (La justicia constitucional), México, UNAM, 2001, p. 58.
} 
bilidad podría descansar en la consideración de que el TC estaría en las mejores condiciones de evitar interferencias o retrasos en el proceso de renovación o sustitución de sus miembros, a lo cual podría incluso proveer dentro del nutrido personal al servicio jurídico del mismo Tribunal, lo que garantizaría el personal de experiencia en la materia necesario para el funcionamiento de la institución.

La propuesta, sin embargo, puede plantear algunos problemas. Para ello, es conveniente traer colación algunas observaciones que se han realizado a esta idea, con motivo de su formulación anterior por quien fuera Presidente del Tribunal Constitucional en 1992, don Francisco Tomás y Valiente, en el marco de un periodo crítico de retraso en la renovación de magistrados a cargo del Congreso ${ }^{63}$.

Entre los problemas que se pueden presentar, se puede destacar el relativo a una cierta pérdida o menoscabo de la necesaria legitimidad democrática o la reproducción de un consenso similar al constituyente, que tiene que acompañar el acto selectivo de magistrados constitucionales, el cual sólo puede venir impreso a través de la participación del Parlamento. Siguiendo esta línea crítica, se diría que esta propuesta favorecería, por otro lado, una práctica que potenciaría el fenómeno corporativista o endogámico en la designación de los magistrados constitucionales ${ }^{64}$.

Las posturas reseñadas poseen, en efecto, cierta contundencia, sin embargo, podrían matizarse de alguna manera, al considerar que la cooptación no pretende fomentar el corporativismo, porque se trata en todo caso, de una salida alternativa al sistema de renovación para evitar su bloqueo, por lo tanto las facultades constitucionales del legislativo y el peso específico de su intervención en la designación de los magistrados no se perderían. Quizá también resulte de interés para cohonestar esta postura con la propuesta, que el Tribunal Constitucional cooptara a los magistrados de entre las propuestas que se hubiesen generado mientras la facultad de designación estaba en sede parlamentaria.

La objeción de la legitimidad democrática podría también atemperarse si se entendiese al sistema democrático en un sentido más amplio y no sólo por aquél que es resultado de las elecciones y el ejercicio del voto popular, esto

${ }^{63}$ En la época, la prensa recogió su declaración sobre la conveniencia de introducir un procedimiento para que la renovación de los magistrados del TC dejara de corresponder, pasado un mes de plazo sin cumplimentarla, al Parlamento y recayera en el propio Tribunal. Ver la nota titulada "Tomás y Valiente propone una fórmula de autorrenovación del Constitucional", El País, 31 de mayo de 1992.

${ }^{64}$ Ver al respecto, Cobo del Rosal, Manuel, "La enfermedad y su remedio anticonstitucional. Sobre la renovación de magistrados del Tribunal Constitucional", El País, 10 de junio de 1992; Pérez Royo, Javier, "Evitar los disparates", El País, 17 de junio de 1992, y del mismo autor, "De mal en peor", El País, 10 de noviembre de1998; Fernández Segado, Francisco, "La estructura orgánica del Tribunal Constitucional"..., p. 446. 
es, que no sólo el Parlamento proporcionaría este tipo de legitimidad, sino también la propia Constitución y el poder que puede reformarla.

Es de reconocer que la propuesta podría también presentar el riesgo de que el Tribunal Constitucional sea expuesto a violentas críticas a raíz de las opciones tomadas en sus designaciones, o bien que el conflicto parlamentario pueda trasladarse al interior del Tribunal. Respecto a la primera posibilidad, habría que tomar en cuenta que el propio acto selectivo de magistrados es objeto de deliberación pública con independencia del órgano que lo ejecute, de ahí precisamente, la exigencia de que el procedimiento sea realizado con todo cuidado.

Respecto a la probable traslación del debate político a la sede plenaria del Tribunal podría decirse que en efecto dicho riesgo existe, sin embargo, el número reducido de integrantes del colegio, su perfil, la forma de adoptar los acuerdos y el funcionamiento de la institución, hacen poco probable vislumbrar un problema en la designación de magistrados con las magnitudes creadas por los partidos políticos en el Parlamento. Por otro lado, confiaría en la resolución del problema apelando a la moderación y prudencia con la que suelen obrar los miembros del Alto Tribunal ante los delicados problemas que les plantean en los procesos constitucionales de los que son competentes.

Finalmente, cabe abordar, así sea de forma muy general, sobre la implementación de la propuesta en el sistema de fuentes. En primer término, se puede advertir que no podría ser generada a través de una reforma a los Reglamentos de las Cámaras parlamentarias en virtud de que al contemplar la participación del Tribunal Constitucional en la cooptación de los magistrados, se rebasa el ámbito de acción de la vía reglamentaria al no constituir el propio TC un interna corporis de la Cámara. Tampoco se considera que la Ley Orgánica del Tribunal Constitucional pueda ser la vía idónea, ya que el modelo de composición del TC viene establecido ipso iure de la Constitución de forma clara y no parece que la previsión del artículo 165 constitucional que prevé que una "ley orgánica regulará el funcionamiento del Tribunal Constitucional, el estatuto de sus miembros, el procedimiento ante el mismo y las condiciones para el ejercicio de las acciones", pueda abarcar la modificación que se propone por esta vía.

Luego la propuesta supondría la necesidad de tramitar una reforma del artículo 159.1 de la Constitución que establece el modelo de composición. La necesidad de la reforma constitucional, sin duda alguna, dificulta las posibilidades de éxito de la propuesta en un futuro previsible dada la complicada tramitación de la reforma constitucional, el clima de crispación política que se percibe en la actualidad y en la poca atención que las fuerzas políticas han puesto en este tema. Por lo que de momento, queda el permanente recurso de acudir a la activa participación ciudadana, a fin de exigir a los partidos políticos su responsabilidad de Estado para dar una mayor importancia al cuidado del Tribunal Constitucional tal y como les ha sido confiado por la Constitución. 